\title{
Evolution of Bombings against Transportation Infrastructure
}

\section{Hill J*}

\author{
AssessAfrica LLC, Ladera Ranch, California, United States
}

${ }^{*}$ Corresponding author: Hill J, AssessAfrica LLC, Ladera Ranch, California, United States, E-mail: AssessAfrica@gmail.com

Citation: Hill J (2016) Evolution of Bombings against Transportation Infrastructure. J Forensic Sci Criminol 4(4): 404. doi: 10.15744/2348-9804.4.404

Received Date: March 12, 2016 Accepted Date: August 30, 2016 Published Date: August 31, 2016

\begin{abstract}
Terrorists and insurgents have proven their ability to develop effective improvised explosive devices, with each configuration providing insight into the type of target and type of attack. Across rail systems, bus networks, and aviation infrastructure, transportation targets throughout Africa are plentiful and have come under attack. The targeting of transportation infrastructure can only be seen as a direct attack against civilians. Even though the conveyance may be funded or operated by the government, the civilians who fill the conveyance or conveyance's 'fixed' sites are affected the most. Because the civilian population is the primary target of terrorist and insurgent attacks against transportation, a collective approach to transportation security is necessary to improve public safety and defeat the networks behind improvised explosive device attacks.
\end{abstract}

Keywords: Terrorists; Transportation infrastructure; Africa; Explosives; Bombing

\section{Introduction}

The transportation infrastructure throughout Africa remains an attractive target for bombings by insurgents and terrorists. Some countries have seen grenade attacks that have resulted in only injuries, while some countries have experienced large vehicle bombings that have resulted in hundreds of injuries and numerous deaths. With insurgencies, explosive devices have been small, complex, and generally target an enemy of the insurgency or small numbers of civilians. With terrorist bombings, the explosive devices have been large, brazen, and targeted at civilian populations in crowded locations. And, these civilian populations are easily targeted within the transportation system. While transportation conveyances continue to be crowded and transportation infrastructure continues to show both expansion and improvement, the transportation system throughout Africa will remain an attractive target.

\section{Improvised explosive device components}

The use of improvised explosive devices is not a rarity, but rather an often-utilized weapon in the terrorist and insurgent arsenal. Improvised explosive device components are often divided into five categories, with various configurations designed for specific types of targets or specific methods of attack. These five component categories are the Switch, Power source, Initiator, Container, and Explosives. These categories also form the acronym SPICE, which was developed by AssessAfrica to separate improvised explosive device components for functional analysis [1]. The switch is used to transfer power or flame to the initiator and can be either electric or non-electric. An electric switch would be used to establish positive-control of the improvised explosive devices functionality, either through controlling the timing or placing the activation trigger in the hands of the bomber. The electric switch could be a digital timer, modified cellular phone, or modified wireless radio system. A non-electric switch may be a slow-burning fuse or manually activating a grenade fuse. With non-electric switches, control of the improvised explosive device's functionality is not absolute, with the time of detonation being established as an estimate. The power source is the component that waits for command from the switch to activate the initiator, so the power source could be any number of batteries or charged capacitors. In some non-electric designs, a flame could be considered the power source, as it begins the transfer of energy in the firing system.

The initiator is the first SPICE component that contains an explosive hazard and is used to detonate the main explosive charge. Initiators consist of small quantities of very sensitive explosive mixtures, all housed in a small, rigid container. These explosive mixtures within the initiator are sensitive to heat and can be homemade, commercial, or military explosives. The initiator itself can also be homemade as well, allowing the difficult-to-acquire component to be improvised. Initiators can be either electric or non-electric, correlating to the type of switch utilized. In an electric initiator, the sensitive explosive mixture will be heated to the point of detonation by a hot wire. In commercial and military electric initiators, the hot wire is often a bridge wire embedded in the sensitive explosive mixtures. In a non-electric initiator, a slow-burning fuse focuses a small flame against the sensitive explosive 
mixture to cause a detonation. If an electric initiator is identified or discovered, this would indicate the bomb maker wanted to establish some type of positive control of the improvised explosive device's functionality and enabling the bomber to be nearby, or far from, the bombing site. If a non- electric initiator is identified, this would indicate that the bomb maker's primary concern is not positive control of timing, but most likely short, approximated estimates of detonation delay where the bomber would be in close proximity to the bombing site.

The container for the improvised explosive device is limited only by the bomb maker's imagination, but the container does help to identify the device's intended function and purpose. If the container is sealed, such as a pipe or steel tube, may be indicative of low explosive filler, like smokeless powder, or indicate the bomber's intention to create large amounts of fragmentation. When the container itself is used to provide fragmentation, the bomb maker is not taking the additional steps to camouflage the item and most likely intends for the improvised explosive device to be used in an overt manner. Containers can also be much larger, such as cars, trucks, or vans. A vehicle used in a bombing can provide the means to transport large amounts of explosives, enable forceful access to the target, and camouflage the bomber in urban environments. Camouflage of smaller improvised explosive devices can also be accomplished when the container matches the environment. A suitcase could be the container when targeting a train, a concealment vest could be used when attempting to reach a target beyond a security checkpoint, or a shopping bag could be the container when targeting a market.

The final SPICE component is the explosive main charge, a material that can be used by the military, various industries, or improvised with common chemicals. These products are generally insensitive to heat, shock, and friction, so an initiator is used to cause detonation. Military explosives can be bare products like SEMTEX or trinitrotoluene, or contained within ordnance like mortars or rockets. The acquisition of military explosives can be difficult, but can be obtained by theft or from unexploded ordnance. Commercial explosives, such as those used in the mining or blasting industries, are often secured in containers at the work site, but opportunities for theft arise when the employees vacate the work site at the end of their shifts. Improvised explosives, also known as homemade explosives, can be created through synthesis or through the physical mixture of precursor materials. Improvised explosives are made from common chemicals like acetone, peroxide, powdered metals, or liquid fuels. Improvised explosives can be sensitive and are generally used in smaller explosive charges, such as those concealed in backpacks, where military and industrial explosives would be more stable and used in any size explosive device from pipe bombs to vehicle bombs (Table 1).

\begin{tabular}{|c|c|c|}
\hline & Name & Examples \\
\hline S & Switch & $\begin{array}{r}\text { Digital timer, modified cellular phone, modified wireless radio } \\
\text { system, time fuse, grenade fuse }\end{array}$ \\
\hline P & Power Source & Battery, capacitor, flame \\
\hline I & Initiator & $\begin{array}{c}\text { Homemade electric/non-electric, commercial electric/non-electric, } \\
\text { military electric/non-electric }\end{array}$ \\
\hline C & Container & Pipe, steel tube, car, truck, van, suitcase, vest, shopping bag \\
\hline E & Explosive & $\begin{array}{c}\text { SEMTEX, trinitrotoluene (TNT), military ordnance, commercial } \\
\text { mining/blasting products, homemade explosives }\end{array}$ \\
\hline
\end{tabular}

Table 1: Improvised explosive device components in SPICE acronym - AssessAfrica, 2016

\section{Improvised explosive device adaptation}

Transportation infrastructure is a target that requires improvised explosive devices to be adapted to the specific conveyance and the conveyance's security practices. The manner a bomber attacks a train may be a crude device placed simply into a suitcase, but the targeting of an airplane would require unique concealment to defeat the security screening process and technologies. The bomb maker's process will also have to be adapted based on the materials available, but the improvisation of explosives and initiators greatly increases the bomb maker's ability to develop an effective improvised explosive device. Switches and power sources are products that can be purchased without arousing any suspicion, so the complete acquisition of SPICE components may never have to require any theft or criminal activity. Bomb makers throughout Africa have proven their ability to create effective improvised explosive devices with both available and improvised components. Successful bomb development often leads to the search for targets where the impact can be maximized and, unfortunately, the transportation networks throughout Africa often meet this criterion.

\section{Rail infrastructure}

Egypt's rail transportation infrastructure has seen numerous explosives-related incidents since 2012. In late September of 2012, six train passengers were injured during an explosion at the Talkha Station in Egypt [2]. During this incident, two passengers were seen handling a suspicious item at the time of the explosion and, during the post-blast investigation, the item was determined to be a homemade grenade. Investigators did not indicate if the homemade grenade was booby-trapped to injure passengers or if the item was merely abandoned. A year later, a catastrophic attack was prevented on the Suez-Ismailia Rail Line when an improvised explosive device was discovered and removed [3]. The improvised explosive device did not appear to utilize homemade explosives and, instead, utilized military explosive ordnance as the main charge. The utilization of ordnance as the main charge is ideal in an 
improvised explosive device, as ordnance is manufactured and the quality of the contained explosives is generally controlled. In the summer of 2014, attacks against rail infrastructure in Egypt had increased. In June of 2014, at least four were injured when four explosive devices detonated at three different metro stations throughout Cairo (Press Trust of India, 2014). Reports indicate the devices utilized homemade explosives and were targeting rush-hour crowds. A short time later, in early July of 2014, five additional people were injured when a concealed improvised explosive device detonated onboard a train in the city of Alexandria [4]. During this attack, reports indicated the improvised explosive device was concealed in a briefcase near a passenger seat. These attacks have evolved from singular explosive devices within a train station, to an improvised explosive device placed under train tracks, to numerous devices at train stations, and concealed bombs onboard trains.

The utilization and dependence on rail transportation infrastructure is set to increase over the next five years. For example, daily ridership in Cairo's metro system has risen to 100,000 per day after the second phase of the Cairo's third metro line was completed [5]. This improvement also added four underground stations to the system. Also, in 2015, the Egyptian government is set to open the Egyptian Academy of Transport Technology to educate rail technicians and engineers. This will further support Egypt's plans to build more train lines, stations, and rail infrastructure.

The Egyptian government has also indicated plans, in collaboration with experts from Europe, to introduce high-speed trains at the end of 2014 [5]. The use of high-speed rail systems could exponentially increase the lethality of improvised explosive devices placed on, under, or alongside tracks. Incidents throughout the world involving track anomalies or high-speed derailment have resulted in high numbers of fatalities, so damage to high-speed trains from terrorist attacks could lead to similar results. If the Egyptian government continues to be a target of insurgents, government funded infrastructure, such as rail expansion or highspeed rail projects, will also remain a target.

\section{Bus infrastructure}

In 2013 and 2014, terrorist attacks against buses and bus infrastructure evolved from singular attacks against buses, to the use vehicle bombs, and the nearly simultaneous attacks of multiple buses. With at least one hundred killed during attacks on bus infrastructure since March of 2013, attacks have become more successful and diverse. Buses and bus stations continue to be an attractive target for terrorists, as these locations and conveyances are often busy and crowded. In March of 2013, a suicide bomber with a vehicle-borne improvised explosive device attacked a bus station in Kano, Nigeria. During this attack, approximately sixty were killed and five buses were destroyed [6]. Just over a year later in April of 2014, another large bombing took place at a bus station in Nigeria. In this attack, the Nyanya Motor Park was attacked and at least seventy-one were killed and over one hundred and twenty were injured [7]. Boko Haram has proven that their improvised explosive device designs are effective and continue to target large gatherings of citizens. Bus stations will, unfortunately, continue to provide Boko Haram with large congregations of people to target. In 2014, Kenya's bus infrastructure was also attacked with improvised explosive devices. In March of 2014, an improvised explosive device was discovered at a bus stop before it exploded [8]. The device appeared to be approximately 13by-18 inches, with red detonating cord and a cellular phone for a switch. Bomb squad personnel responded to the site and safely removed the explosive device. A similar sized explosive device could have been used in the early May of 2014 attacks against buses in Mombasa and Nairobi. On May 4, 2014, an improvised explosive device was used against a bus that had just arrived at a bus station in Mombasa, Kenya [9]. Local reporting indicated the explosive device was possibly thrown into the bus' door as soon at it had parked, leaving at least three killed and at least twenty injured. Attacks were escalated the next day, as Nairobi saw two buses attacked with improvised explosive devices within a few minutes of one another [10]. During this attack, at least two were killed and at least sixty were injured. These attacks have evolved from targeting a bus stop, to targeting a single bus, to executing nearly simultaneous attacks against two buses at the same time.

\section{Aviation infrastructure}

Attacks against aircraft in Africa are rare, but attacks against aviation infrastructure have become common in Somalia, with some spillover violence into Kenya. From early 2013 to spring of 2014, Al-Shabaab has claimed, or been linked to, fifty-eight attacks against airports in Somali and Kenya [11]. These attacks include thirty-four aimed at the exterior of the airport, twenty-one near the airport or on airport roads, and zero targeting the secured interior of the airport (Figure 1) [11].

While many of the exterior attacks against airports may be targeting military forces located on the flight line or in airport buildings, Al-Shabaab has proven that airports are soft targets if attacked from the outside with the use of rockets, mortars, and small arms. In one of the most invasive Al-Shabaab attacks on the exterior of an airport, bombers utilized a covertly placed improvised explosive device. In January 2014, an explosion took place at a coffee shop on the exterior of the Jomo Kenyatta International Airport in Nairobi, Kenya [12]. In this incident, an explosive device was placed into trashcan near the counter of the busy coffee shop and luckily, caused no injuries. There was little damage to the facility, with only the trashcan and an overhead light being destroyed in the attack. These attacks against aviation infrastructure have slowly crept further into the facilities, evolving from standoff attacks to covert attacks on airport grounds. If terrorist groups continue to find success as attacks are moved into the secured interiors of airports, AssessAfrica believes attacks will transition further into aviation infrastructure and begin to directly target travelers or aircraft. 


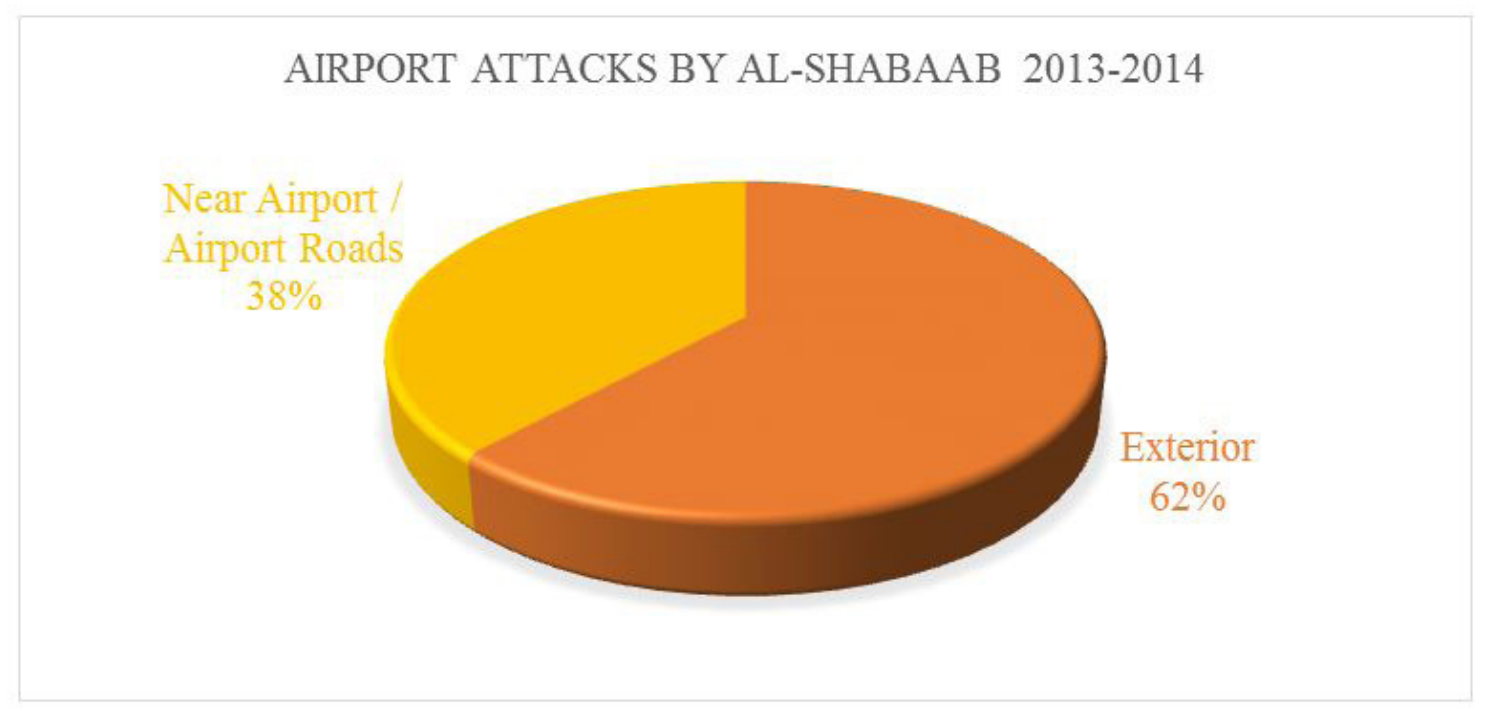

Figure 1: Airport attacks by AL-Shabaab 2013-2014

\section{Protective measures}

Physical security measures are effective at providing some protection for venues like bus stations, train stations, and airports. This may be accomplished through facility design, access control systems, barriers, or a visible and engaged security presence. But these locations are 'fixed', unlike the transportation route itself. As soon as the bus leaves the station and enters open roads, or the train departs the station and is moving along its route, the terrorist's targeting and attack opportunities grow immensely. With bus transportation, buses move along scheduled routes while mixing with commercial and commuter traffic. Any time and location along the bus' route could present a hazard. With rail transportation, the train moves along a fixed path at scheduled times, moving through a diverse landscape that can be both urban and rural. And, similar to the targeting of buses, any location along the route can be targeted. In the aviation sector, security practices have been both shared and streamlined. But, some countries have established Air Marshal programs to protect aircraft during flight, but this is not a security practice that is easily translated to ground-based transportation. This is not only an African issue, but also an international issue that is difficult to both assess and counter. Physical security efforts may be easily bypassed once en route, so passenger and transportation employee awareness becomes paramount. Suspicious items, unattended items, improvised explosive device characteristics, and suspicious activity indicator posters or public address system announcements at transportation facilities can help to increase passenger knowledge and awareness. All employees who work in or around transportation infrastructure should also be knowledgeable about suspicious activity and threat recognition, as each employee's unique role, amount of passenger interaction, and knowledge of vulnerabilities make the employee a much better sensor. Employees like bus drivers and train car attendants are often considered to be the predominant sensor to suspicious activity, but all employees who interact with passengers, provide cleaning services, or conduct maintenance are also ideally positioned to recognize suspicious activity. For example, an individual cleaning a train station's restroom may recognize a suspicious item placed behind a toilet or an individual conducting maintenance of train tracks may recognize indications of rail tampering or evidence of unauthorized, under-rail digging. These employees spend their day seeing the transportation infrastructure in a 'normal' manner, so each is better positioned to recognize when anomalies are present within the system.

\section{Conclusion}

The terrorist use of explosives in Africa spans many civilian, police, and military venues, but the targeting of transportation infrastructure can only be seen as a direct attack against civilians. The conveyance may be funded or operated by the government, making it a target of insurgents as well, but the civilians who fill the conveyance or conveyance's 'fixed' sites are affected the most. Because the civilian population is the primary target of attacks against transportation, a collective approach to transportation security is necessary. While bombers throughout Africa have proven their ability to deploy effective improvised explosive devices within the transportation environment, the bomb maker's device configuration and camouflage could mean that any part of the transportation infrastructure can be targeted. Buses can be targeted by an occupant or along the route, trains can be targeted in the passenger cars or on the tracks, and aviation infrastructure can be targeted on the ground or in the air. Because one cannot predict the exact time and place chosen by the bomber, one cannot also predict who will detect the placement or plot. To better secure the entire transportation network with a collective approach, suspicious activity and suspicious item awareness campaigns for the public, transportation employees, and all levels of security forces can empower detection and prevent future tragedies associated with the terrorist use of improvised explosive devices. 


\section{About the author}

For nearly 13 years, Jonathan Hill has served with the United States Air Force as an Explosive Ordnance Disposal technician, served as a bomb disposal contractor in Kurdistan, and has led an Explosives Specialist team with the Department of Homeland Security. Mr. Hill started AssessAfrica, LLC in early 2014 to share terrorist incident analysis and bombing-related research with the public. Mr. Hill completed over 440 days of consecutive analysis before transitioning to larger research projects, resulting in invitations to speak about African terrorism to audiences around the world. The views expressed in this product are solely those of AssessAfrica, LLC and do not necessarily represent the views of the United States government.

\section{References}

1. AssessAfrica (2015) IED Components Analysis Series. In AssessAfrica - Analysis.

2. Al-Youm A (2012) Six injured in bomb explosion in Talkha train station. In Egypt Independent.

3. Ahram Online (2013) Egypt suspends Suez-Ismailia railway activity following attempted explosion. In ahramonline.

4. Deshmukh J (2014) Blast in Egypt train as police crush pro-Morsi protests. In The Jakarta Post.

5. Abu al-Khair W (2014) Egypt opens second stage of third metro line. In Al-Shorfa.

6. Adamu L (2013) Nigeria: Dozens Killed in Kano Bus Station Blasts. In allAfrica.

7. Onuoha F (2014) Boko Haram and Nyanya Bomb Blast. In Aljazeera Center for Studies.

8. Associated Press (2013) Kenya calm but tense following election verdict. In CBCnews.

9. Reuters in Mombasa (2014) Kenya: deadly blast at Mombasa bus terminal. In theguardian.

10. Associated Press (2014) Bombs Explode on Two Buses Packed With Kenya Commuters. In The New York Times.

11. Navanti Group LLC (2010-2013) Data extracted from 2013-2014. In Native Prospector.

12. Ombati C (2014) Mystery surrounds discovery of male body after Jomo Kenyatta International Airport 'blast'. In Standard Digital News.

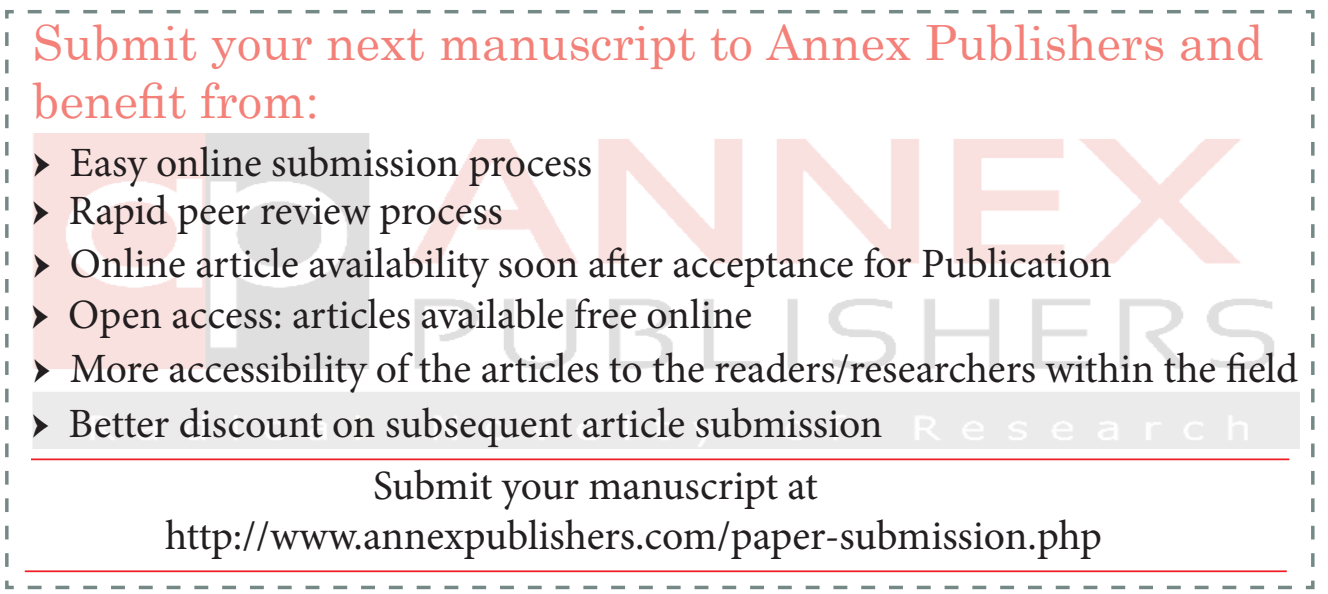

